International Journal of Instruction e-ISSN: 1308-1470 • www.e-iji.net
July $2020 \bullet$ Vol.13, No.3

p-ISSN: 1694-609X

pp. $861-876$

Received: $22 / 09 / 2019$

Revision: 09/03/2020

Accepted: $23 / 03 / 2020$

OnlineFirst:24/05/2020

\title{
Effects of Students' Motivation and Engagement on Students' Satisfaction in a Lecture: Empirical Analysis
}

\section{Nnamdi Obiosa}

Faculty of Business and Management, Regent's University London, London, United

Kingdom,obiosan@regents.ac.uk

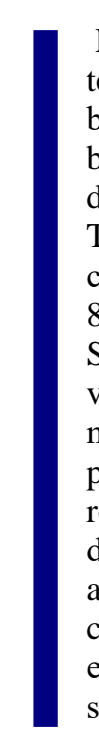

Lecture is one of the oldest means of instruction and most extensively used teaching method on campuses of Higher Education Institutions (HEI). There have been many studies about students' motivation, engagement and satisfaction in HEI but none of these have focused on these three variables in relation to lecture despite the prominence and history of lecture, thus creating a gap in the literature. This empirical analysis was aimed at predicting and explaining of the target construct, students' satisfaction. Data was collected through survey of students in 80 different class lectures. Partial least square structural equation modelling (PLSSEM) was used as an analytical tool. The constructs and their measurement variables were first developed using focus group. The hypothesized conceptual model had two independent constructs, students' motivation and engagement as predictors of the target construct. The measurement variables were found to be reliable and valid. The structural model had substantial predictive power of the dependent construct students' satisfaction, indicating high level of predictive accuracy in the explained variance of the dependent construct. The results confirmed that students' motivation and engagement significantly had positive effects on students' satisfaction in a class lecture and simultaneously they were substantially strong predictors of students' satisfaction.

Keywords: students' satisfaction, motivation, engagement, lecture, PLS-SEM

\section{INTRODUCTION}

Lecture is one of the oldest means of instruction (McKeachie, 1980; Augustinien, 2004) and it is still the most extensively used teaching method on campuses of Higher Education Institutions (HEI) (Lammers \& Murphy, 2002; Eagan et al., 2014). One major challenge facing lecturers in a class lecture is the issue students' satisfaction as students query the value if not aligned to their needs. It is important to understand the factors affecting students' satisfaction in a lecture and what strategies to adopt to enhance the students learning experience and satisfaction. The introduction of teaching excellence framework in United Kingdom (UK) has made this more imperative. The

Citation: Obiosa, N. (2020). Effects of Students' Motivation and Engagement on Students' Satisfaction in a Lecture: Empirical Analysis. International Journal of Instruction, 13(3), 861-876. https://doi.org/10.29333/iji.2020.13357a 
significance of this can be found in the words of Sinclaire (2014, p. 2) "student satisfaction can be viewed both as an outcome of the learning process and a requirement for successful learning". The problem of lecturing large class and ensuring high level of students' satisfaction has become more challenging and exacerbating due to diversity of students especially in UK and USA HEI where there has been influx of foreign students. Lecturers should be sensitive to the issue of students' satisfaction in a class lecture given the implication negative impression would have in their overall rating and impact on student recruitment. Zedda et.al. (2017) emphasised that the need to measure students' satisfaction has gained consideration in HEI as a result of the positive benefits related to it, which includes retention and recommendations to other prospective students. Lecturing is a core activity within HEI and students' perception of how well this activity is undertaken will have an impact on overall rating of any institution. Mikulić et.al. (2015) maintained that understanding of predictors of student satisfaction is a requirement for designing improvement programmes as it is vital for HEI to identify causes of student satisfaction or dis-satisfaction. Motivation will drive students' willingness to align with learning process as well as their attentiveness and participation. Students' lack of motivation to learn during lecture could have negative effect on learning. Smilkstein (1989), in a study asked a group of students on higher education to list stages of learning process; and this resulted in the development of a six-step process. Top of this list is motivation, signifying that it is the pillar on which subsequent steps are built upon. In classroom lecture, the lecturer is prime transmitter of students' motivation, but does this have an impact on students' satisfaction? Reeve (2005, p. 125), in his writing noted that engagement is "a term that captures the intensity and emotional quality people show when they initiate and carry out activities, such as learning in school". A highly engaged student is active and tenacious in undertaking tasks and adopts deep cognitive tactics whereas highly disengaged student is passive, shows adverse emotions and appears to employ shallow cognitive tactics (Greene \& Miller, 1996). Motivation and engagement so far discussed are generally associated with positive student outcomes but does this lead to students' satisfaction in a class lecture? This research will attempt to answer this question.

There have been many studies about students' motivation (Brewer et.al., 2005; Kusurkar et.al., 2013), students' engagement (Daniel et.al., 2010; Heaslip et.al., 2014;) and students' satisfaction (DeShields.et.al., 2005; Sears et.al., 2017) in HEI but none of these have focused on these three variables in relation to class lecture despite the fact that lecture is the most widely used instructional method. The research objective is empirically to evaluate the effects of students' motivation and engagement on students' satisfaction in a class lecture. It will focus on the prediction and explanation of the target construct, students' satisfaction; and theory development. This will contribute directly to the quality of students' learning. The research will help lecturers to undertake selfevaluation of their practice as well as assist HEI to structure a development plan for their classroom lecturers. It is of great importance for lecturers and HEI to understand areas that can improve total students' satisfaction; and quality class lecture is one of the main areas. However, there has been a gap in the literature as there has not been an empirical study on the determinants of students' satisfaction in class lecture hence the 
importance of this research. For the fact that lecturers differ so much in their teaching practices due to freedom HEI offer, further makes understanding the determinants of students' satisfaction in class lectures very significant so that lecturers can adopt a successful approach.

\section{THEORETICAL BACKGROUND}

Understanding of the indicators of instructional qualities and student satisfaction is very valuable in an academic environment as this will enhance the attainment of learning outcomes. Cambridge dictionary online (2019) defines a lecture as "a formal talk on a serious subject given to a group of people, especially students". Student satisfaction within a class lecture can be described as the unobservable feeling of pleasure and achievement of intention. Sweeney and Ingram (2001, p. 57) stated that satisfaction is "the perception of enjoyment and accomplishment in the learning environment". Xiao and Wilkins (2015) expressed the view that student satisfaction is attained when real or perceived experiences fulfil or surpass personal expectations. Student satisfaction in a class lecture is a multi-faceted construct with various predictors and measurement indicators.

There are many drivers of overall students' satisfaction in HEI, but various studies have found that teaching quality is about the most important source of student satisfaction (Deshields et al., 2005; Green et. al., 2015; Sears et.al., 2017; Sutherland et. al., 2018). It is evident that teaching performance of a lecturer in lecture will have major impact on student satisfaction. Lecturers delivering class lectures should be conversant with contents of the lecture to be delivered. You ought to have good subject knowledge of what you are to teach as inability to show masterly of the subject will disengage and demotivate students; and impact their satisfaction. It is important to plan your lecture against time allocated so that you have enough time to cover the topics you feel are important and allow substantial time for students' questions (Christensen, 1988). Questions and discussions during lecture are potent form of student engagement. For class lecture, the lecturer should plan lecture in blocks of not more than 15 minutes, vary pace and style as well as avoid lecturing verbatim from slide. These characteristics are very strong and positive attributes to possess as it stimulates and enhances student's ability to understand and ultimately their satisfaction. Penner (1984) pointed out that on average student's attention span is between ten and twenty minutes. Lecturer's ability not to read from pre-prepared script will create active engagement with students as this will imply preparing lecture for the ear and not the eye. Day (1980) mentioned that reading from text will make your students feel disengaged.

Yean and Chui (2016) alluded to the fact that motivation is significantly related to students' satisfaction. Being able to motivate students will inspire them to achieve and be content. Tasgin and Coskun (2018) explained that motivation is a significant variable that impacts all stages of learning. Kaufman and Dodge (2009) in describing motivation expressed the view that intrinsic motivation relates to inner state that stimulates behaviour. Students need to be motivated through the lecturer's show of enthusiasm and assured that by engaging with the lecture their objective of enrolling in the course will be achieved as Ericksen (1978, p. 3) clearly stated that "Effective learning in the classroom depends on the teacher's ability ... to maintain the interest that brought 
students to the course in the first place". Lecturer's expectations of achievement by students should be clearly set high but achievable as lecturer's standards, when properly set, motivates and will influence how well students perform. Students will be motivated and encouraged into action as they see possibility of higher achievement (Forsyth \& McMillan, 1991). Lecturers should also emphasis well need for further reading and attempting seminar questions. Clear and stimulating case should be made as to benefits and impact of such readings which could prove to be motivational for students just as Lowman (1984) expressed. DeShields et.al. (2005), discussed motivation in relation to students' satisfaction and related Herzberg et.al. (1967) concept of motivating and hygiene factors to student satisfaction and dissatisfaction, with 'satisfiers' being categorized as motivators and 'dissatisfiers' categorized as 'hygiene' factors.

Engagement of students in class involves making students active with tasks and activities in relation to their studies (Lei et.al., 2018). Heaslip et.al. (2014) expressed that in the constructive model of learning, engagement and attention by students are vital in their education. By building learner participation into class lecture through group exercises you are encouraging active learning (Silberman, 1996). This also clearly supports the position of Biggs and Tang (2007, p. 94) when they said that "being active while learning is better than being inactive". These activities actively engage students, creating platform to make them think intuitively about concepts and theories they are learning thus giving the lecturer feedback in class on students' understanding of the material. It also helps to instil problem-solving skills in students as it offers them opportunity to put theory into practice which will enhance their learning experience and satisfaction in line with the philosophy of problem-based learning (Savery, 2015). These activities enable the lecturer to re-capture students' attention especially given the fact that Bligh (2000) mentioned that students' attentiveness in lecture rapidly decreases after ten minutes of listening. A disengaged student will end up unsatisfied. One of the objectives of this study is to understand the significance of student engagement, such as classes exercises and interactions, during lecture on students' satisfaction.

Intriguingly, no study has looked empirically at class lecture, which is at the heart of teaching quality, in relation to students' satisfaction and its predictors. These facets of teaching quality that are most significant to students is devoid of detail in existing literature (Sutherland et. al., 2018). Understanding the effects of students' motivation and engagement on students' satisfaction in a class lecture will contribute immensely to overall students' satisfaction and provide departments and lecturers with the information necessary to optimize the allocation of their limited resources in the context of competing demands. This study will add to the literature in this aspect of instructional technique that takes place so often in our University campuses.

\section{METHOD}

The test for the hypothesised conceptual model for this research was undertaken through an empirical research based on surveys amongst students enrolled in a business faculty in a London university. Researchers have used variants of the structural equation modelling (SEM) in educational research (Kusurkar et.al., 2013; Sebastianelli et.al., 2015; Yousefi et.al., 2019). This research used PLS-SEM as a statistical analysis technique for understanding data and the relation. It is a multivariate statistical analysis 
that allow you to simultaneously analyse multiple variables (Hair et.al., 2017). PLSSEM is used for making prediction or exploratory modeling and theory development which contrasts with covariance-based structural equation modeling (CB-SEM), which is used mainly for theory and concept testing and confirmation (Garson, 2016; Hair et.al., 2017). The PLS-SEM uses Path Models which are diagrams that visualize variables and the relationships between them. These variables are classified as either latent variables or indicator/measurement variables. The latent variables referred to as constructs are not directly observable or measured while the indicators which are observable are directly measured proxy variables that contain the raw data.

\section{Conceptual, Structural and Measurement Models}

Based on literature reviewed on previous studies on students' motivation, engagement and satisfaction valuable information was learnt on their relationships and measurements. However, there is a lack of detailed understanding of what measurement variables should be used to measure these unobservable constructs especially in a class lecture as well as the conceptual directions of the constructs. To successfully navigate this hurdle, an exploratory method via focus group was needed to gain robust understanding and identify appropriate measurement variable for the latent variables as well as confirm the conceptual framework since such knowledge is not available in existing literatures. This approach has been used by various researchers on students' satisfaction in the past (Oldfield \& Baron, 2000; Yean \& Chui, 2016) and this study adopted similar approach to identify predictors and determine the measurement variables of the constructs. The survey questionnaires relating to measurement variables of the unobservable constructs were based on variables identified by the focus group. The focus group comprised two sets of final year BA finance students each comprising 35 and 34 students respectively. The determination of which of the constructs are exogenous or endogenous and their sequence in the structural model in the hypothesized conceptual model for this research is based on theory in the literature, logic and confirmation from participants of the focus group. The hypothesized conceptual model to meet the research objective is shown in fig. 1

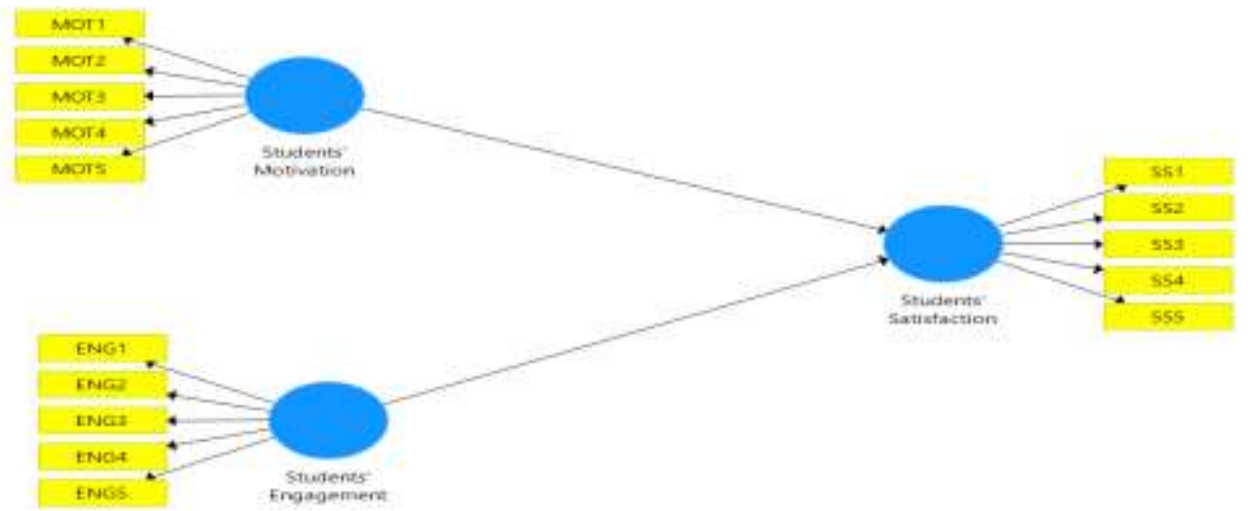

Figure 1

Hypothesized Conceptual Model 
Based on the list of possible measurement variables from literature reviewed, the experience of the researcher and opportunity to add their own variables, the focus group participants were asked to identify themes that could be used to measure each of the unobservable constructs. For the constructs, Students' Motivation (MOT), Students' Engagement (ENG) and Students' Satisfaction (SS), the focus group participants identified the following measurement variables for each of them as shown in table 1;

Table 1

Latent \& Measurement Variables

\begin{tabular}{ll}
\hline Constructs & \multicolumn{1}{c}{ Indicators } \\
\hline MOT & $\mathrm{MOT}_{1}$ - Expectations were clearly set high but achievable for students. \\
& $\mathrm{MOT}_{2}$ - Lecture was stimulating with use of real-life examples. \\
& $\mathrm{MOT}_{3}$ - Emphasis on need to know to ensure career progression on graduation and \\
& linking lecture to employability. \\
& $\mathrm{MOT}_{4}$ - Avoid asking questions which appear threatening leading to students being \\
& withdrawn. \\
& $\mathrm{MOT}_{5}$ - Emphasis on need for further reading and attempting seminar questions. \\
\hline ENG & $\mathrm{ENG}_{1}$ - Introduced group exercises at intervals for students to do during lecture. \\
& $\mathrm{ENG}_{2}$ - Blank spaces in teaching slides for students to fill in answers to questions. \\
& $\mathrm{ENG}_{3}$ - Encourages debate among students through questioning to get them involved. \\
& $\mathrm{ENG}_{4}$ - Does not lecture verbatim from slides except for emphasis \\
& $\mathrm{ENG}_{5}$ - Allow students to ask questions as lecture progresses and/or create time at \\
the end to take students' questions.
\end{tabular}

\section{Study Hypotheses}

The following hypothesis were developed for the study;

H1: Students' motivation significantly has positive effect on students' satisfaction in class lecture.

H2: Students' engagement significantly has positive effect on students' satisfaction in class lecture.

H3: Jointly students' motivation and engagement are predictors of students' satisfaction in class lecture.

\section{Data Collection}

The data for this study were collected from students of a business faculty at a University in London. The data were collected through survey. The survey was designed to measure the unobserved latent variables. Five measurement variables identified for each construct by the participants of the focus group (shown in Table 1) were used to measure each of the constructs. The survey was administered to students in 80 different class lectures. The sizes of the classes ranged from 35 to 250 students each. Students in each class lecture were individually asked to rate the class on each of the measurement 
variables relating to each of the constructs. The rating was based on 7-point Likert scale with 1 - strongly disagree to 7 - Strongly agree. In each of these classes at least $60 \%$ of students completed the survey. The responses for each measurement variable for each class was totalled and the average used as a score for that measurement variable. The sample size met the minimum sample size requirement based on the 10 times rule (Hair et.al., 2017); using the largest number of structural paths directed at a construct will result in 20 observations ( 2 x 10) against the sample size of 80 used. Alternatively, using the $\mathrm{G}^{*}$ Power program as explained by Hair et.al. (2017), requires 33 observations to detect $R^{2}$ values of 0.25 , assuming a significance level of $5 \%$ and a statistical power of $80 \%$ since we have 2 independent variables in the structural model.

\section{FINDINGS AND DISCUSSION}

\section{Path Model Estimation}

In this research, the path model is made up of the structural model and the measurement models. The data was run using SmartPLS 3 software (Ringle et.al., 2015).

\section{Evaluation of Reflective Measurement Models - ENG, MOT and SS.}

The examination of the estimates will enable one to evaluate the reliability and validity of the reflective constructs' measures, the systematic evaluation is based on Hair et.al. (2017). Table 2 is the results summary of the internal consistency and convergent validity assessment.

Table 2

$\underline{\text { Results Summary of Internal Consistency and Convergent Validity }}$

\begin{tabular}{|c|c|c|c|c|c|}
\hline \multirow{3}{*}{$\begin{array}{l}\text { Latent } \\
\text { Variables }\end{array}$} & \multirow[b]{3}{*}{ Indicators } & \multicolumn{2}{|c|}{ Convergent Validity } & \multicolumn{2}{|c|}{ Internal Consistency Reliability } \\
\hline & & Indicator Reliability & AVE C & Cronbach's Alpha & $\begin{array}{l}\text { Composite } \\
\text { Reliability }\end{array}$ \\
\hline & & Outer loadings $>0.70$ & $>0.50$ & $0.70-0.90$ & $0.70-0.90$ \\
\hline \multirow{5}{*}{ ENG } & ENG1 & 0.791 & \multirow{5}{*}{0.576} & \multirow{5}{*}{0.816} & \multirow{5}{*}{0.871} \\
\hline & ENG2 & 0.748 & & & \\
\hline & ENG3 & 0.737 & & & \\
\hline & ENG4 & 0.801 & & & \\
\hline & ENG5 & 0.714 & & & \\
\hline \multirow{5}{*}{ MOT } & MOT1 & 0.762 & \multirow{5}{*}{0.640} & \multirow{5}{*}{0.859} & \multirow{5}{*}{0.899} \\
\hline & MOT2 & 0.828 & & & \\
\hline & MOT3 & 0.800 & & & \\
\hline & MOT4 & 0.813 & & & \\
\hline & MOT5 & 0.793 & & & \\
\hline \multirow{5}{*}{ SS } & SS1 & 0.759 & \multirow{5}{*}{0.580} & \multirow{5}{*}{0.817} & \multirow{5}{*}{0.873} \\
\hline & SS2 & 0.735 & & & \\
\hline & SS3 & 0.708 & & & \\
\hline & SS4 & 0.735 & & & \\
\hline & SS5 & 0.862 & & & \\
\hline
\end{tabular}

The assessment to establish internal consistency reliability to ensure that assessment tool produced stable and consistent results includes Cronbach's Alpha and Composite 
reliability. Table 2 shows Cronbach's Alpha values for all constructs and it was confirmed that all reflective measurement models are within the $0.70-0.90$ threshold specified by Hair et.al. (2017). Composite reliability criterion requires composite value of between $0.70-0.90$ to ensure internal consistency reliability (Hair et.al., 2017); all constructs are in conformity as shown in table 2 . In relation to convergent validity, average variance extracted (AVE) was used to determine whether each latent variable explains more than $50 \%$ of their indicator. AVE values shown in table 2 indicate that they are all above required minimum of 0.50 as stipulated by Hair et.al. (2017). This confirms that all three reflective constructs have good levels of convergent validity. Additionally, indicator reliability was assessed based on expectation that latent variable variance should explain at least $50 \%$ of the indicator. This means that loadings of manifest variables should not be less than 0.70 (Henseler et.al., 2012; Hair et.al., 2017). The outer loadings which are depicted in table 2 confirms that all reflective measurement indicators were above the threshold of 0.70 which indicates adequate levels of indicator reliability. Furthermore, the reflective models were assessed for discriminant validity, which was used to determine if each construct is empirically distinct from other constructs in the model. The following measures were analysed; Cross-loadings, Fornell-Larcker criterion and heterotrait-monotrait ratio (HTMT), the results summary is shown in table 3 .

Table 3

Results Summary of Discriminant Validity

\begin{tabular}{|c|c|c|c|c|c|c|c|c|c|c|}
\hline \multicolumn{11}{|c|}{ Discriminant Validity } \\
\hline & & \multicolumn{3}{|c|}{ Cross-loadings } & \multicolumn{3}{|c|}{ Fornell-Larcker Criterion } & \multicolumn{3}{|c|}{$\begin{array}{r}\text { Heterotrait-Monotrait } \\
\text { Ratio (HTMT) }\end{array}$} \\
\hline \multirow{6}{*}{ ENG } & & ENG & MOT & SS & ENG & MOT & SS & ENG & MOT & SS \\
\hline & ENG1 & 0.791 & 0.280 & 0.506 & & & & & & \\
\hline & ENG2 & 0.748 & 0.318 & 0.503 & & & & & & \\
\hline & ENG3 & 0.737 & 0.332 & 0.586 & 0.759 & & & & & \\
\hline & ENG4 & 0.801 & 0.394 & 0.535 & & & & & & \\
\hline & ENG5 & 0.714 & 0.276 & 0.450 & & & & & & \\
\hline \multirow{5}{*}{ MOT } & MOT1 & 0.244 & 0.762 & 0.510 & & & & & & \\
\hline & MOT2 & 0.408 & 0.828 & 0.550 & & & & & & \\
\hline & MOT3 & 0.339 & 0.800 & 0.493 & 0.425 & 0.800 & & 0.502 & & \\
\hline & MOT4 & 0.447 & 0.813 & 0.629 & & & & & & \\
\hline & MOT5 & 0.252 & 0.793 & 0.625 & & & & & & \\
\hline \multirow{5}{*}{ SS } & SS1 & 0.534 & 0.541 & 0.759 & & & & & & \\
\hline & SS2 & 0.575 & 0.533 & 0.735 & & & & & & \\
\hline & SS3 & 0.430 & 0.529 & 0.708 & 0.685 & 0.709 & 0.762 & 0.828 & 0.838 & \\
\hline & SS4 & 0.450 & 0.501 & 0.735 & & & & & & \\
\hline & SS5 & 0.598 & 0.592 & 0.862 & & & & & & \\
\hline
\end{tabular}

For cross-loading, loading for each indicator is considerable higher than all crossloadings with other constructs indicating that discriminant validity holds. For FornellLarcker criterion, the square root of each latent construct's AVE is larger than the correlation of the specific construct with any other reflective constructs in the model. This confirms that all three reflective constructs have enough discriminant validity. The 
stricter heterotrait-monotrait (HTMT) ratio was assessed and a conservative HTMT value of 0.85 was used as the threshold (Henseler et.al., 2015) for this research, all values were below the threshold value of 0.85 . Furthermore, HTMT values were tested to see whether they are significantly different from 1 by computing bootstrap confidence interval. Bootstrapping set-up was two tailed and significance level of 0.05. Result of Confidence Intervals Bias Corrected is shown in table 4, neither of the confidence interval includes the value 1 , which further supports discriminant validity.

Table 4

Confidence Intervals Bias Corrected

\begin{tabular}{llcccc}
\hline & Original Sample (O) & Sample Mean (M) & Bias & $2.5 \%$ & $97.5 \%$ \\
\hline Mot -> Eng & 0.502 & 0.513 & 0.011 & 0.315 & 0.658 \\
\hline SS -> Eng & 0.828 & 0.830 & 0.001 & 0.684 & 0.929 \\
\hline SS -> Mot & 0.838 & 0.840 & 0.002 & 0.686 & 0.953 \\
\hline
\end{tabular}

In conclusion, these various results show that the measurement variables of all reflective constructs presented in the path model were reliable and valid.

\section{Evaluation of the Structural Model}

Having obtained satisfactory results for reliability and validity of constructs measures, discussion and evaluation of structural model results were undertaken. This involved evaluating the model's predictive capabilities and determining whether structural relationships are significant and meaningful (Hair et.al., 2017). The PLS-SEM path result is shown in fig. 2.

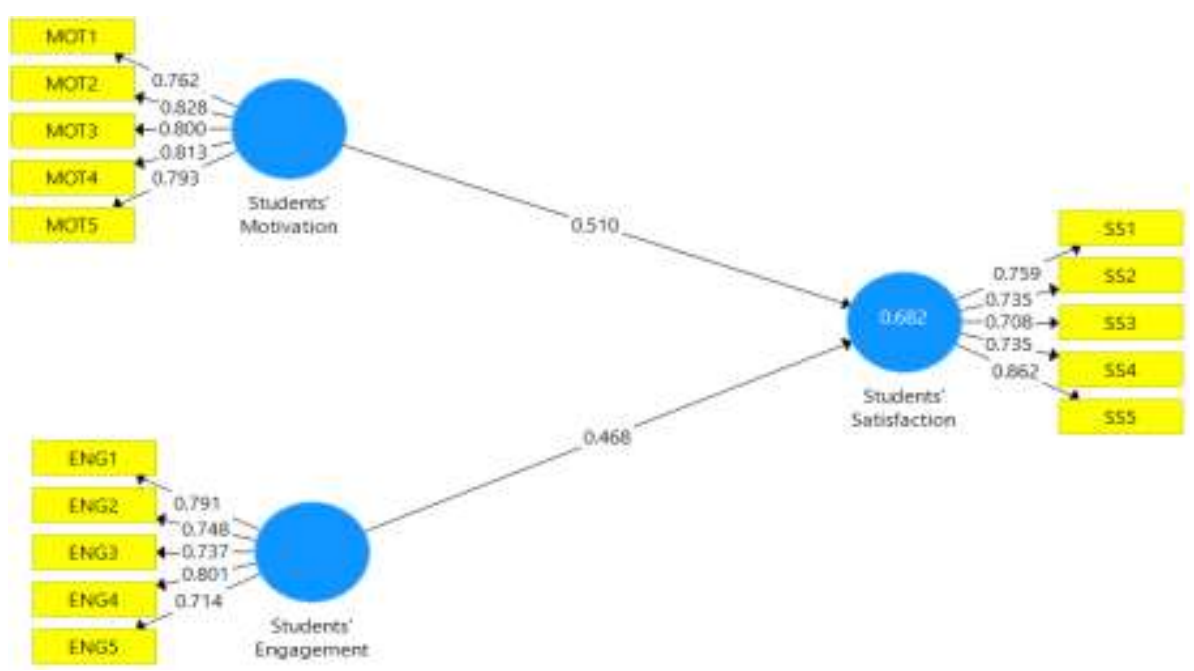

Figure 2

\section{PLS-SEM Path Result}

The structural model was first assessed for any collinearity issues. This was analysed using variance inflation factor (VIF) inner values. The threshold used for this analysis is 
$0.20>$ VIF $<5$ (Hair et.al., 2017). The result is shown in table 5 and all inner VIF values are below the threshold of 5, as well as each being above the lower bound of 0.20 . This ascertains that there were no collinearity issues in the structural model and the evaluation of the structural model can continue.

Table 5

Collinearity Statistics (VIF) Inner Values



\section{Size and significance of path coefficients}

The statistical significance of path coefficients relates to the conceptual model hypothesized relationship (fig.1) and highlights the relative importance of an exogenous construct on an endogenous construct. Table 6 shows the path coefficients of each independent variable to dependent variable. In terms of relative importance, MOT, with value of 0.510 , is slightly of higher importance than ENG with value of 0.468 to target construct SS. Both constructs can be described as having major bearings on SS.

Table 6

Path Coefficient \& Significance Testing Results

\begin{tabular}{llllll}
\hline \multicolumn{1}{l}{ Hypotheses } & Path Coefficients & $t$ Values & $p$ Values & Significance $(\mathrm{p}<0.05)$ \\
\hline H1 & ENG-> SS & 0.468 & 6.813 & 0.000 & Yes \\
\hline H2 & MOT -> SS & 0.510 & 6.482 & 0.000 & Yes \\
\hline
\end{tabular}

Based on path coefficients result, it is clear, that the relationships between MOT and ENG to target construct SS are quite significant. This is based on the rule of thumb that values above 0.20 are significant while values below 0.10 are usually not significant (Hair et.al., 2017). Additionally, bootstrapping procedure was used to obtain coefficient's standard error which is the ultimate determinant of significance. Table 6 shows the bootstrapping Path Coefficient results. All relationship in structural model, namely ENG to SS and MOT to SS are significant at 5\% level since their $\boldsymbol{p}$ values were less than 0.05 (Hair et.al., 2017). This established that $\mathrm{H} 1$ and $\mathrm{H} 2$ are fully supported in this study and confirmed that both MOT and ENG significantly have positive effects on SS in class lecture; this in line with the research works of Eom et.al., (2006) and Cheong \& Ong (2016) in terms of general relationship between these constructs in educational field.

\section{Coefficients of determination $\left(\boldsymbol{R}^{2}\right)$}

The $R^{2}$ value is key criterion for assessing structural model and is a measure of the predictive power of the model. The thrust for evaluating the structural model is the level of explained variance of dependent constructs which is represented by the coefficient. As a rule of thumb, $R^{2}$ value of endogenous constructs of $0.75,0.50$ or 0.25 can be respectively described as substantial, moderate or weak (Hair et.al., 2011). The $R^{2}$ value is shown in table 7 and following rule of thumb, $R^{2}$ value of SS (0.682), our target construct, can be described as moderately substantial. Furthermore, it can be expressed 
that the two constructs MOT and ENG jointly explain $68.2 \%$ of the variance of the endogenous construct SS. This established that $\mathrm{H} 3$ is fully supported in this study and confirms that, jointly MOT and ENG are predictors of SS in a class lecture and is consistent with the findings of preceding researches in terms of the direction of the relationship between the two independent constructs and the dependent construct in educational research (Eom et.al., 2006; Yean \& Chui, 2016).

Table 7

R Square Value

\begin{tabular}{lllll}
\hline \multicolumn{2}{l}{ Hypothesis } & R Square & R Square Adjusted & Decision \\
\hline H3 & Students' Satisfaction & 0.682 & 0.674 & Supported \\
\hline
\end{tabular}

The $f$ square effect size expresses the effect of an omitted endogenous construct from the model on $R^{2}$ change to determine whether the omitted construct has substantial impact on endogenous constructs. Decision guideline for assessing $f^{2}$ effect according to Cohen, (1988) are small $\left(f^{2}=0.02\right)$, medium $\left(f^{2}=0.15\right)$, and large $\left(f^{2}=0.35\right)$. Table 8 shows $\mathrm{f}$ square results and both ENG and MOT, as predictors, have large effect sizes on $\mathrm{SS},(0.566)$ and (0.670) respectively. This additionally confirms H1, H2 and H3.

Table 8

F Square Values



Stone and Geisser $Q^{2}$ test was used to evaluate predictive relevance of structural model. Using blindfolding procedure, a path model has predictive relevance for a specific reflective endogenous latent variable if the $\mathrm{Q}^{2}$ value is greater than zero and all negative $Q^{2}$ values reflect absence of predictive relevance. $Q^{2}$ results are shown in table 9 , the value for SS is above zero (0.359) indicating predictive relevance. This confirms the model's predictive relevance in relation to the target construct and further confirms H3.

Table 9

$Q^{2}$ Values - Construct Crossvalidated Redundancy

\begin{tabular}{llll} 
& SSO & SSE & $\mathrm{Q}^{2}(=1-\mathrm{SSE} / \mathrm{SSO})$ \\
\hline ENG & 400.000 & 400.000 & \\
\hline MOT & 400.000 & 400.000 & 0.359 \\
\hline SS & 400.000 & 256.204 & \\
\hline
\end{tabular}

The $q^{2}$ effect sizes was evaluated to determine relative impact of predictive relevance and as stated by Hair et.al. (2017, p. 207), $q^{2}$ effect size can be defined as

$$
q^{2}=\frac{Q_{\text {included }}^{2}-Q_{\text {excluded }}^{2}}{1-Q_{\text {included }}^{2}}
$$

Following rules of thumb, values of $0.02,0.15$ and 0.35 implies the exogenous latent variable has small, medium or large predictive relevance respectively, for a specific 
endogenous latent variable. This is computed manually as SmartPLS 3 software is not equipped to provide them. From results shown in table 10 , the relative $q^{2}$ effect sizes of ENG and MOT can be considered medium in terms of their contribution to SS, further confirming $\mathrm{H} 1$ and $\mathrm{H} 2$.

Table 10

The $q^{2}$ effect sizes

\begin{tabular}{lc}
\hline & SS \\
\hline ENG & 0.145 \\
\hline MOT & 0.157 \\
\hline
\end{tabular}

\section{CONCLUSION AND SUGGESTIONS}

This research investigated the effects of students' MOT and ENG on SS in a class lecture using PLS-SEM as an analytical tool. The objectives are the prediction and explanation of the target construct SS and theory development. The conceptual model has two constructs, MOT and ENG as predictors of the target construct SS. Their measurement variables were reliable and valid thus providing support for their inclusion in the path model; there were no collinearity issues in the structural model. From analysis of the size and significance of path coefficients, it was confirmed that both MOT and ENG significantly have positive effects on the target construct SS and their relationship is significant at 5\% level thus confirming hypotheses 1 and 2 . With regards to relative importance of these predictor variables to the target construct, MOT is slightly higher than ENG. The import of this, is that in terms of hierarchy, lecturers and HEI should prioritise their efforts in the above order to achieve high level of students' satisfaction. The researcher can empirically assert that the structural model has moderately substantial predictive power of the dependent construct, SS, with $R^{2}$ value of 0.682 thus confirming hypothesis 3 . With such a value, the structural model shows high level of predictive accuracy in the explained variance of the dependent construct. Being that the model has few exogenous constructs (two) pointing towards the target construct and still had a predictive value of $68.2 \%$ means that, indeed, MOT and ENG are key variables to enhance by lectures for the attainment of students' satisfaction in class lectures. In terms of explanatory power, using F square, both ENG and MOT have large effect sizes on SS meaning they each have substantive impact on SS further confirming all the hypotheses. It is confirmed that, the endogenous construct SS has predictive relevance since it's $Q^{2}$ value is greater than zero. This confirms that the model accurately predicts data not used in the model estimation which is required for the empirical results to be accepted. The $q^{2}$ effect sizes of the exogenous latent variables ENG and MOT on the target endogenous construct SS are medium in terms of relative impact of their predictive relevance.

Based on the coefficient of determination, path coefficients, their significance and importance, the conceptual model is well substantiated empirically. From the empirical result, a theory can be propounded that, individually, students' motivation and engagement are moderately strong predictors of students' satisfaction; and jointly they are substantially strong predictor of students' satisfaction. This research is important in the sense that though all of us as lecturers may be experts at certain instructional 
techniques, there is an expectation that we must all be able to lecture and if we must lecture, we are under obligation to ensure students' satisfaction. It is highly recommended that lecturers should pay attention to the requirements of all indicator variables of MOT and ENG and be compliant in order to enhance SS. The exogenous constructs are pivotal to success of a lecturer's job and students' feelings to each of their measurement variables are critical for lecturing success. Applying the results of this research by lecturers will enable them to excel in the end of semester students' module evaluation feedback as addressing findings in this study will ensure high scores for the lecturers.

The measurement variables for each construct were identified by the participants of a focus group, these may not be exhaustive which is a limitation of the study, however, this creates opportunity for further research, other researchers may wish to innovate on this by using additional or different measurement variables.

\section{REFERENCES}

Augustinien, A. (2004). Lecture as a traditional form of studies in higher school and its importance to evolve while facing knowledge society. Social Sciences, 44(2), 72-81

Biggs, J., \& Tang, C. (2007). Teaching for quality learning at university. Buckingham: SRHE and Open University Press.

Bligh, D. A. (2000). What's the use of lectures? San Francisco, CA: Jossey-Bass.

Brewer, E. W., \& Burgess, D. N. (2005) Professor's role in motivating students to attend class. Journal of STEM Teacher Education, 42(3): 3.

Cheong, K. C., \& Ong, B. (2016). An evaluation of the relationship between student engagement, academic achievement, and satisfaction. In S. F. Tang, \& L. Logonnathan (Eds.), Assessment for learning within and beyond the classroom: Taylor's 8th teaching and learning conference 2015 proceedings (pp409-416). Singapore: Springer ScienceBusiness Media.

Christensen, N. (1988). Nuts and Bolts of Running a Lecture Course. In A. L. Deneff, C. D. Goodwin, \& E. S. McCrate (Eds.), The academic handbook. Durham, N.C.: Duke University Press.

Cohen, J. (1988). Statistical power analysis for the behavioral sciences. Mahwah, NJ: Lawrence Erlbaum.

Exeter, D. J., Ameratunga, S., Ratima, M., Morton, S., Dickson, M., Hsu, D., \& Jackson, R. (2010) Student engagement in very large classes: the teachers' perspective. Studies in Higher Education, 35(7), 761-775. doi: 10.1080/03075070903545058.

Day, R. S. (1980). Teaching from notes: Some cognitive consequences. In W. J. McKeachie (Ed.), New directions for teaching and learning: Learning, cognition, and college teaching (pp.95-112): San Francisco: Jossey-Bass. 
DeShields, O. W., Kara, A., \& Kaynak, E. (2005). Determinants of business student satisfaction and retention in higher education: applying Herzberg's two-factor theory. International Journal of Educational Management, 19(2), 128-139.

Eagan, M. K., Stolzenberg, E. B., Berdan Lozano, J., Aragon, M. C., Suchard, M. R., \& Hurtado, S. (2014). Undergraduate teaching faculty: The 2013-2014 HERI faculty survey. Los Angeles: Higher Education Research Institute, UCLA.

Eom, S. B., Wen, H. J., \& Ashill, N. (2006). The determinants of students' perceived learning outcomes and satisfaction in university online education: An empirical investigation. Decision Sciences Journal of Innovative Education, 4, 215-235.

Ericksen, S. C. (1978). The lecture. Memo to the faculty, no. 60. Ann Arbor: Center for Research on Teaching and Learning, University of Michigan.

Forsyth, D. R., \& McMillan, J. H. (1991). Practical proposals for motivating students. New Directions in Teaching and Learning, 45, 53-65. doi:10.1002/t1.37219914508.

Garson, G. D. (2016). Partial least squares regression and structural equation models. Asheboro: Statistical Associates.

Green, H. J., Hood, M., \& Neumann, D. L. (2015). Predictors of student satisfaction with university psychology courses: A review. Psychology Learning and Teaching, 14(2), 131-146.

Greene, B. A., \& Miller, R. B. (1996). Influences on achievement: Goals, perceived ability, and cognitive engagement. Contemporary Educational Psychology, 21, 181192.

Hair, J. F., Hult, G. T. M., Ringle, C. M., \& Sarstedt, M. (2017). A primer on partial least squares structural equation modeling (PLS-SEM). Thousand Oaks, CA: Sage.

Hair, J. F., Ringle, C., \& Sarstedt, M. (2011). PLS-SEM: Indeed a silver bullet. Journal of Marketing Theory \& Practice, 19(2), 139 - 151.

Heaslip, G., Donovan, P., \& Cullen, J. G. (2014). Student response systems and learner engagement in large classes. Active Learning in Higher Education, 15(1), 11-24. https://doi.org/10.1177/1469787413514648.

Henseler, J., Ringle, C. M., \& Sarstedt, M. (2012). Using partial least squares path modeling in advertising research: Basic concepts and recent issues. In S. Okazaki (Ed.), Handbook of research on international advertising (pp.252-276). Edward Elgar publishing.

Henseler, J., Ringle, C. M., \& Sarstedt, M. (2015). A new criterion for assessing discriminant validity in variance-based structural equation modeling. Journal of the Academy of Marketing Science, 43(1), 115-135.

Herzberg, F., Mausner, B., \& Snyderman, B. B. (1967). The motivation to work. New York: Wiley. 
Kaufman, A., \& Dodge, T. (2009). Student perceptions and motivation in the classroom: Exploring relatedness and value. Social Psychology of Education, 12(1), 101-112.

Kusurkar, R. A., Ten Cate, T. J., Vos, C. M., Westers, P., \& Croiset, G. (2013). How motivation affects academic performance: a structural equation modelling analysis. Advances in Health Sciences Education: Theory and Practice, 18(1), 57-69. doi:10.1007/s10459-012-9354-3.

Lammers, W. J., \& Murphy, J. J. (2002). A profile of teaching techniques used in the university classroom: A descriptive profile of a US public university. Active Learning in Higher Education, 3(1), 54-67. https://doi.org/10.1177/1469787402003001005.

Lecture. (2019). In dictionary.cambridge.org Retrieved from https://dictionary.cambridge.org/dictionary/english/lecture.

Lei, H., Cui, Y., \& Zhou, W. (2018). Relationships between student engagement and academic achievement: A meta-analysis. Social Behavior and Personality: An International Journal, 46, 517-528.

Lowman, J. (1984). Mastering the techniques of teaching. San Francisco: Jossey-Bass.

McKeachie, W. J. (1980). Improving lectures by understanding students' information processing. New Directions for Teaching and Learning, 2, 25-35. doi:10.1002/tl.37219800204.

Mikulić, J., Dužević, I., \& Baković, T. (2015). Exploring drivers of student satisfaction and dissatisfaction: an assessment of impact-asymmetry and impact-range. Total Quality Management \& Business Excellence, 26(11/12), 1213 - 1225.

Penner, J. G. (1984). Why many college teachers cannot lecture. Springfield, Ill.: Thomas.

Reeve, J. (2005). Understanding motivation and emotion. Hoboken, NJ: Wiley.

Ringle, C. M., Wende, S., \& Becker, J.-M. (2015). "SmartPLS 3." Boenningstedt: SmartPLS GmbH, http://www.smartpls.com.

Savery J. R. (2015). Overview of problem-based learning: Definitions and distinctions. The Interdisciplinary Journal of Problem-Based Learning, 1(1), 5-15.

Sears, C. R., Boyce, M.A., Boon, S.D., Goghari, V.M., Irwin, K., \& Boyes, M. (2017). Predictors of student satisfaction in a large psychology undergraduate program. Canadian Psychology/Psychologie canadienne, 58(2), 148-160.

Sebastianelli, R., Swift, C., \& Tamimi, N. (2015) Factors affecting perceived learning, satisfaction, and quality in the online MBA: A structural equation modeling approach. Journal of Education for Business, 90(6), 296-305. DOI: 10.1080/08832323.2015.1038979.

Silberman, M. (1996). Active learning: 101 strategies to teach any subject. Boston: Allyn and Bacon. 
Sinclaire, J. K. (2014). Student satisfaction with online learning: Lessons from organizational behavior. Research in Higher Education Journal, 23, 1-20.

Smilkstein, R. (1989). The natural process of learning and critical thinking. Gamut, 38, 26-29.

Sutherland, D., Warwick, P., Anderson, J., \& Learmonth, M. (2018). how do quality of teaching, assessment, and feedback drive undergraduate course satisfaction in U.K. business schools? A comparative analysis with nonbusiness school courses using the U.K. national student survey. Journal of Management Education, 42(5), 618-649. https://doi.org/10.1177/1052562918787849.

Sweeney, J. C., \& Ingram. D. (2001). A comparison of traditional and web-based tutorials in marketing education: An exploratory study. Journal of Marketing Education, 23(1), 55-62.

Tasgin, A., \& Coskun, G. (2018). The relationship between academic motivations and university students' attitudes towards learning. International Journal of Instruction, 11(4), 935-950. https://doi.org/10.12973/iji.2018.11459a.

Yean, W., \& Chui, E. (2016). An exploratory path model of social work students' satisfaction with field education experience in China. Social Work Research, 40(3), 135145 .

Yousefi, M., \& Abdullah, A. G. K. (2019). The impact of organizational stressors on job performance among academic staff. International Journal of Instruction, 12(3), 561576. https://doi.org/10.29333/iji.2019.12334a.

Xiao, J., \& Wilkins, S. (2015). The effects of lecturer commitment on student perceptions of teaching quality and student satisfaction in Chinese higher education. Journal of Higher Education Policy \& Management, 37(1), 98 - 110.

Zedda, M., Bernardelli, S., \& Maran, D. A. (2017). Students' satisfaction with the group work method and its performance evaluation: A survey in an Italian University. International Journal of Instruction, $10(3), \quad 1-14$. https://doi.org/10.12973/iji.2017.1031a. 